\title{
UPAYA PENINGKATAN PRODUKSI MEBEL PADA UMKM KOTA KUPANG BERBASIS TEKNOLOGI TEPAT GUNA
}

\author{
Nursalim*1, Agusthinus S. Sampeallo ${ }^{2}$, Abdul Wahid ${ }^{3}$, Nixson J. Meok ${ }^{4}$ \\ ${ }^{1,2}$ Jurusan Teknik Elektro, Fakultas Sains dan Teknik, Universitas Nusa Cendana \\ ${ }^{3}$ Jurusan Teknik Fisika, Fakultas Sains dan Teknik, Universitas Nusa Cendana \\ ${ }^{4}$ Jurusan Teknik Elektro, PTK FKIP, Universitas Nusa Cendana \\ Kupang-NTT, Telp. 085239065458 \\ "Email : nursalim@staf.undana.ac.id
}

\begin{abstract}
Abtract
Macro development both nationally in general and East Nusa Tenggara (NTT) in particular has shown a change in an increasingly good direction in various fields. However, the development of this region still requires hard work from various groups, especially Micro, Small and Medium Enterprises (MSMEs) in the face of local competition and free competition. The Regional Superior Product Development Program (PPPUD) aims to increase production output by accelerating the production process of MSMEs with modern, technology-based furniture businesses. This PPPUD partner is UD. Gusti Karya, who is one of the SMEs in Kupang City. The method used in this activity is to apply appropriate technology equipment with a more modern system compared to the equipment that partners have. The expected output from this program is to increase production so as to increase income from partners. Based on the results of evaluations conducted after this activity it was found that, with the existence of this activity, the production performance of partners increased to 40 percent from the previous one.
\end{abstract}

\begin{abstract}
Abstrak
Perkembangan makro baik nasional pada umumnya dan Nusa Tenggara Timur (NTT) khususnya telah memperlihatkan adanya perubahan ke arah yang makin baik dalam berbagai bidang. Namun demikian, pembangunan daerah ini masih membutuhkan kerja keras dari berbagai kalangan terutama Usaha Mikro Kecil Menengah (UMKM) dalam menghadapi persaingan lokal maupun persaingan bebas. Program Pengembangan Produk Unggulan Daerah (PPPUD) ini bertujuan untuk meningkatkan hasil produksi dengan mempercepat proses pengerjaan produksi UMKM usaha mebeler berbasis teknologi tepat guna yang modern. Mitra PPPUD ini adalah UD. Gusti Karya yang merupakan salah satu pelaku UMKM di Kota Kupang. Adapun metode yang digunakan pada kegiatan ini adalah menerapkan peralatan teknologi tepat guna dengan sistem yang lebih modern dibandingkan dengan peralatan yang mitra miliki. Luaran yang diharapkan dari program ini adalah peningkatan produksi sehingga dapat meningkatkan penghasilan dari mitra. Berdasarkan hasil evaluasi yang dilakukan setelah kegiatan ini diketahui bahwa dengan adanya kegiatan ini, kinerja produksi mitra meningkat sampai 40 persen dari yang sebelumnya.
\end{abstract}

Kata kunci-PPPUD, Masyarakat Ekonomi Asean; UMKM, mebeler kayu jati

\section{PENDAHULUAN}

Perkembangan makro baik nasional pada umumnya dan Nusa Tenggara Timur (NTT) khususnya telah memperlihatkan adanya perubahan-perubahan ke arah yang makin baik dalam berbagai bidang. Namun demikian, pembangunan daerah ini masih membutuhkan kerja keras dari berbagai kalangan terutama Usaha Mikro Kecil Menengah (UMKM) dalam menghadapi persaingan bebas dan lebih khusus menghadapi Masyarakat Ekonomi ASEAN (MEA) yang sudah mulai berlaku di tahun 2016 (Usman, 2016; Zulyanto, 2016) . MEA memiliki dua dampak bagi kehidupan masyarakat yakni, bias positif dan juga dampak negatif dari pergulatan perdagangan bebas itu. MEA sendiri diyakini akan membuat masyarakat untuk terus meningkatkan kualitas hidupnya, baik kualitas personal maupun produk-produk agar mampu bersaing dengan bangsa lain (Asrial, 2017) 
Kayu Jati adalah merupakan jenis hasil hutan terbanyak kedua di Provinsi Nusa Tenggara Timur (NTT) setelah jenis hasil hutan Rimba Campuran. Data (BPS NTT, 2017) tentang statistik pertanian provinsi NTT menyebutkan bahwa produksi kayu jati pada tahun 2017 mencapai 1.986 .78 m3. Memang jika dilihat dari kontribusi subsektor kehutanan, hasil hutan NTT memang masih relatif kecil terhadap PDRB yaitu sebesar 0.15 persen. Namun seiring perkembangan dari UMKM usaha mebeler, maka budidaya hutan terutama jenis pohon jati putih semakin digemari oleh masyarakat karena omzet yang di hasilkan sangat menjanjikan. Hal ini terasakan oleh Arifin yang telah menghasilkan $14-50$ juta per bulan dari usaha pembibitan pohon kayu jati yang dimilikinya (POS KUPANG.COM, 2016).

Bahan mebel dari kayu jati saat ini makin diminati warga Kota Kupang, karena selain dapat dibuat sesuai selera konsumen, kayu jati juga merupakan merupakan jenis kayu yang kuat dan tahan terhadap jamur, rayap, dan serangga (Hunggurami, Utomo, \& Messakh, 2016; Tanubrata, 2015; Wahyudi, Priadi, \& Rahayu, 2014). Karena keistimewaan inilah yang membuat kayu jati banyak dijadikan sebagai bahan baku utama pembuatan mebel. Hal ini juga diungkapkan oleh Sulur, pemilik Mega Mebel kepada pos kupang (POS KUPANG.COM, 2011). Menurut Sulur bahwa hasil mebel jati yang dimilikinya mampu laku terjual hingga puluhan unit per bulannya. Hal senada juga disampaikan oleh bapak Gabriel D.H Lopo selaku pemilik UD. Gusti karya yang merupakan mitra UMKM pelaksana Program Pengembangan Produk Unggulan Daerah (PPPUD) saat ini. Menurut pengakuan mitra bahwa sejak dia mendirikan usaha mebel didirikannya dari 1997 sampai saat ini belum pernah sepi dari orderan pelanggan. Padahal menurut mitra, bahwa perkembangan usaha mebel saat ini telah berkembang sangat pesat sehingga hampir di setiap sudut kota kupang dapat dijumpai industri-industri mebel yang berbahan baku yang sama. Namun karena tingginya minat dari masyarakat kota kupang saat ini, sehingga mereka dapat tetap bertahan sampai saat ini. Bahkan menurut mitra, hasil kerajinan mebel yang dihasilkannya bukan hanya dikenal di sekitar kota kupang, namun hasil mebel mereka juga telah sangat dikenal sampai keluar kota kupang, seperti di kota maumere yang ada di pulau flores.

Program ini bertujuan untuk meningkatkan mutu serta mempercepat proses pengerjaan produksi UMKM usaha mebeler. Karena menurut mitra bahwa kerajinan mebeler saat ini sangat digemari oleh masyarakat kota kupang, sebab selain kuat, mebel dapat dibuat sesuai selera konsumen. Hal ini dibuktikan oleh mitra yang sudah memulai usahanya selama 21 tahun tanpa sepinya pesanan. Adapun cara peningkatan kualitas yang akan diterapkan adalah dengan melakukan peremajaan peralatan yang mempunyai teknologi yang lebih modern dengan peralatan yang ada saat ini. Selain itu sistem manajemen dan pemasaran juga akan di perbaiki, karena selama ini mitra hanya menggunakan sistem manajemen secara manual dan pemasaran yang hanya dapat menjangkau pemasaran lokal saja. Luaran yang diharapkan dari program ini adalah peningkatan kualitas serta pemasaran yang menjangkau daerah yang lebih luas sehingga dapat meningkatkan omset dari mitra.

\section{METODE}

Metode yang digunakan dalam program PPPUD ini adalah metode mekanisasi yakni melakukan peremajaan mesin tepat guna dengan teknologi yang lebih modern. Pemilihan metode ini didasarkan pada uraian permasalahan yang dihadapi oleh mitra. Adapun sistematika metode yang diterapkan adalah sebagai berikut:

a. Penerapan mesin-mesin produksi untuk mempercepat pekerjaan di UMKM Gusti karya guna menghasilkan papan dan balok kayu sesuai dengan kebutuhan.

b. Pendampingan dan monitoring terhadap penggunaan alat diterapkan pada UMKM untuk menjamin bahwa operasional alat berjalan optimal guna peningkatan kapasitas produksi.

\section{HASIL DAN PEMBAHASAN}

Penyelesaian kegiatan PPPUD tahun pertama ini didasarkan pada tujuan dan target usulan yang telah disusun sebelumnya. Adapun tujuan dan target kegiatan PPPUD tahun pertama yakni menambah dan menerapkan mesin tepat guna yang berteknologi modern untuk mempercepat proses produksi pada mitra, sehingga dengan demikian dapat meningkatkan hasil produksi mitra. Untuk itu sebelum melakukan penerapan teknologi, maka terlebih dahulu pengabdi melakukan koordinasi 
dengan mitra untuk menentukan jenis mesin yang di inginkan agar pengerjaan dapat lebih cepat dari sebelumnya.

\section{Pekerjaan lantai dasar}

Untuk mendukung penggunaan mesin yang berteknologi tepat guna pada mitra, kegiatan pertama yang dilakukan adalah melakukan perbaikan pada lantai dasar ruang workshop sebagai tempat dudukan mesin agar mesin dapat digunakan dan bekerja secara maksimal. Adapun urutan pelaksanaan pekerjaan lantai dasar pada ruang workshop ini adalah sebagai berikut:

\section{a. Pengurugan Tanah Timbunan}

Pekerjaan lantai dasar ini dimaksudkan untuk memperlancar proses pekerjaan dan menstabilkan dudukan mesin yang akan diterapkan. Proses pengerjaan ini dimulai dengan melakukan pengurugan atau pemadatan tanah menggunakan metode preloading dengan menggunakan timbunan tanah (Sandhyavitri, Gunawan Wibisono, \& ST Rioputra, 2009), sehingga beban yang dipikul permukaan tanah dapat merata. Gambar 7 memperlihatkan proses pengurugan tanah timbunan, sedangkan gambar 8 memperlihatkan hasil pengurugan tanah..

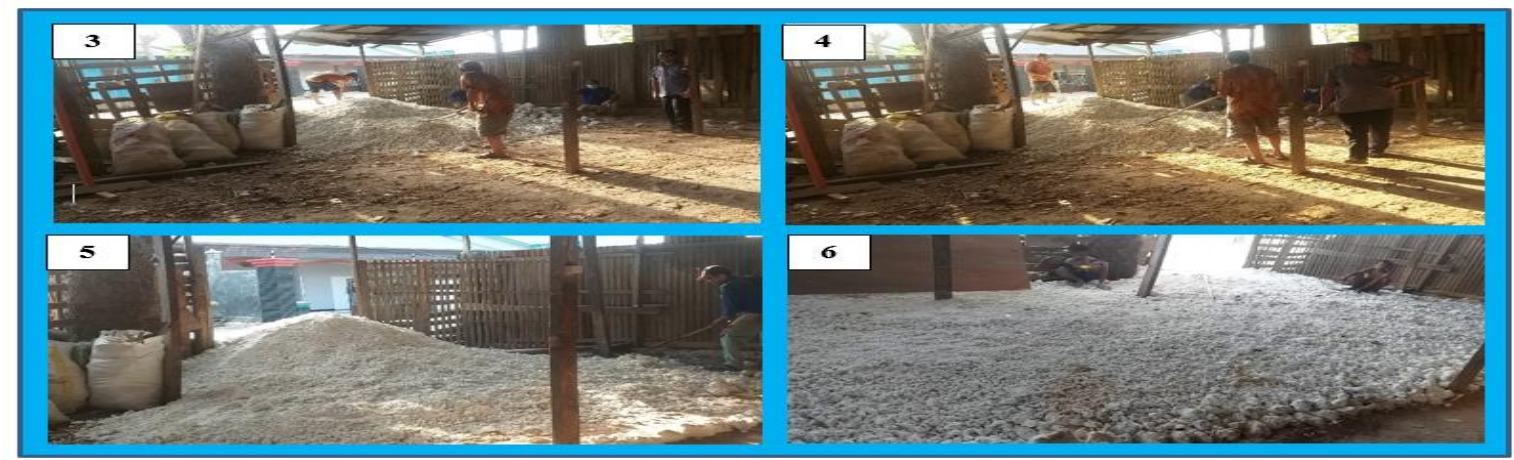

Gambar 7. Pengurugan tanah timbunan pada ruang workshop UMKM Mitra

\section{b. Plesteran Semen Lantai Workshop Mitra}

Pengerjaan ini dilakukan untuk meratakan lantai dasar tempat kerja (Workshop), sehingga dudukan mesin dapat stabil dan seimbang sehingga dalam penggunaanya, mesin tidak mudah bergerak atau bergoyang. Selain itu, dengan plesteran lantai ini dapat membuat pekerja lebih nyaman bekerja dalam workshop. Adapun proses pengerjaan plesteran lantai dasar ini dapat dilihat pada gambar 9.

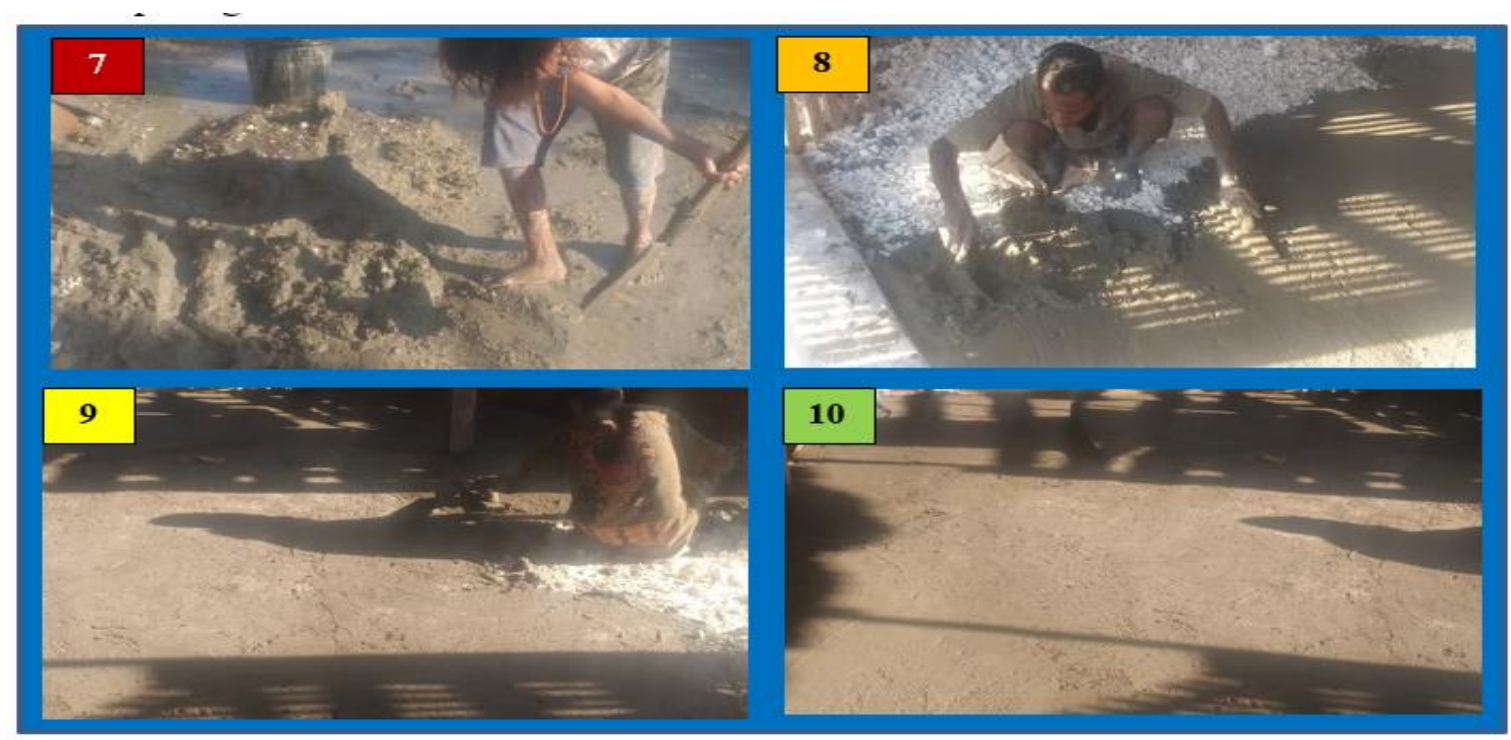

Gambar 9. Pengerjaan Plesteran Semen Lantai pada ruang workshop UMKM Mitra 
DINAMISIA - Jurnal Pengabdian Kepada Masyarakat Vol. 3, No. 2 Desember 2019, Hal. 258-265

\section{Pengadaan dan perakitan Mesin Produksi}

Setelah pekerjaan lantai dasar pada ruang workshop mitra selesai dan siap digunakan, maka kegiatan selanjutnya adalah perakitan mesin tepat guna yang diawali dengan urutan kegiatan sebagai berikut:

\section{a. Pengadaan Mesin Produksi}

Tahapan ini diawali dari pengambilan dan pengiriman mesin produksi dari bengkel ke workshop mitra dengan menggunakan angkutan lokal seperti gambar 10.

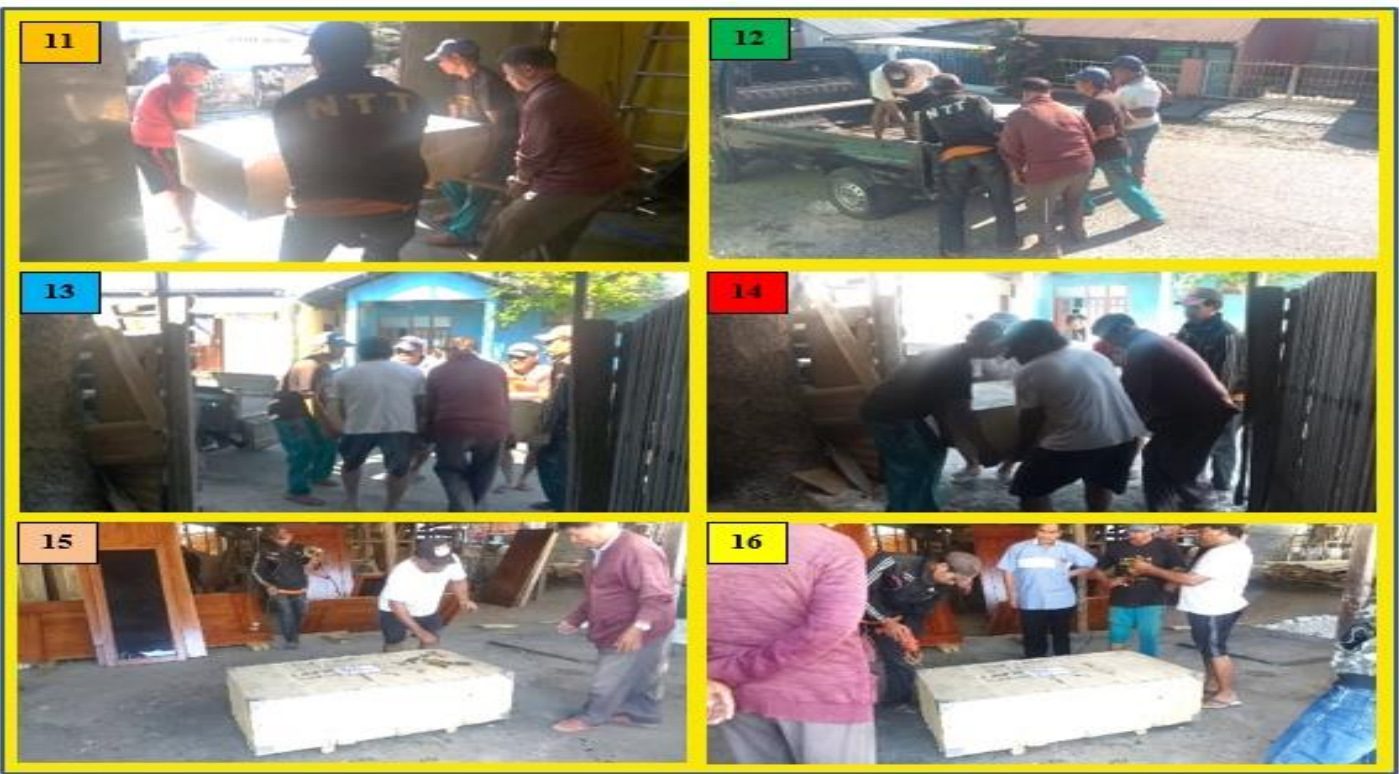

Gambar 10. Pengambilan dan pengiriman mesin produksi ke mitra

\section{b. Perakitan Mesin Produksi}

Perakitan diawali dengan merangkai kaki mesin pada tempat yang telah ditentukan sebelumnya. Perakitan ini melibatkan ketua dan anggota pengabdi beserta narasumber yang telah berpengalaman dalam perakitan mesin, sehingga perakitan mesin produksi ini dapat berjalan lancar serta dapat berfungsi sesuai dengan yang diharapkan. Adapun gambar perakitan mesin produksi ini diperlihatkan pada gambar 11.

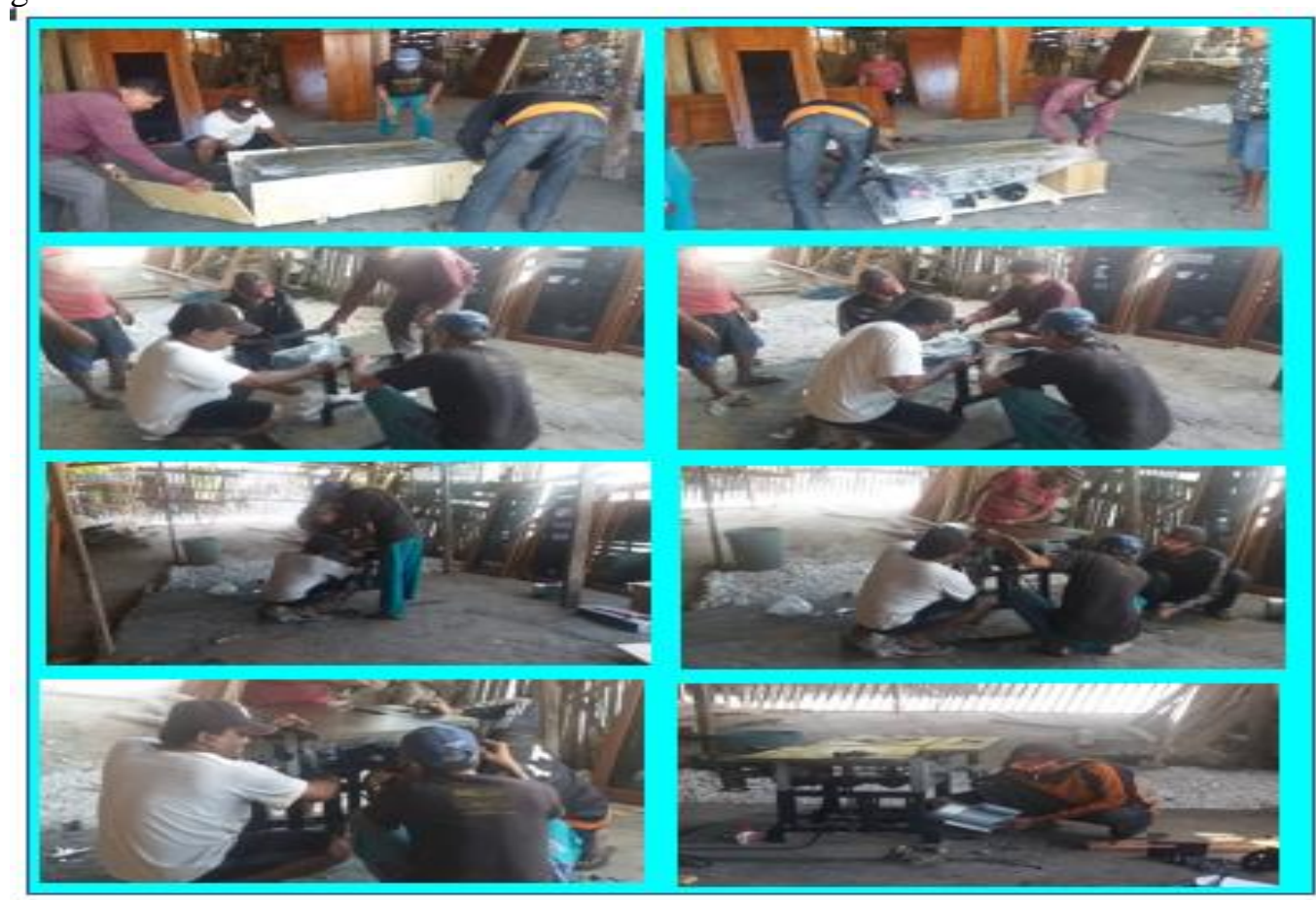

Gambar 11. Proses perakitan mesin produksi mitra 
DINAMISIA - Jurnal Pengabdian Kepada Masyarakat Vol. 3, No. 2 Desember 2019, Hal. 258-265

\section{c. Pengerjaan Instalasi Listrik}

Setelah tahap perakitan mesin produksi selesai, maka tahap selanjutnya adalah pemasangan instalasi listrik sebagai catu daya ke mesin produksi. Jenis instalasi yang dipasang adalah instalasi satu phase yang dilengkapi dengan panel aksesoris yang dipasang di dekat mesin. Hal ini bertujuan untuk meningkatkan keamanan serta memudahkan pengontrolan mesin. Adapun proses pemasangan instalasinya dapat dilihat pada gambar 13 .

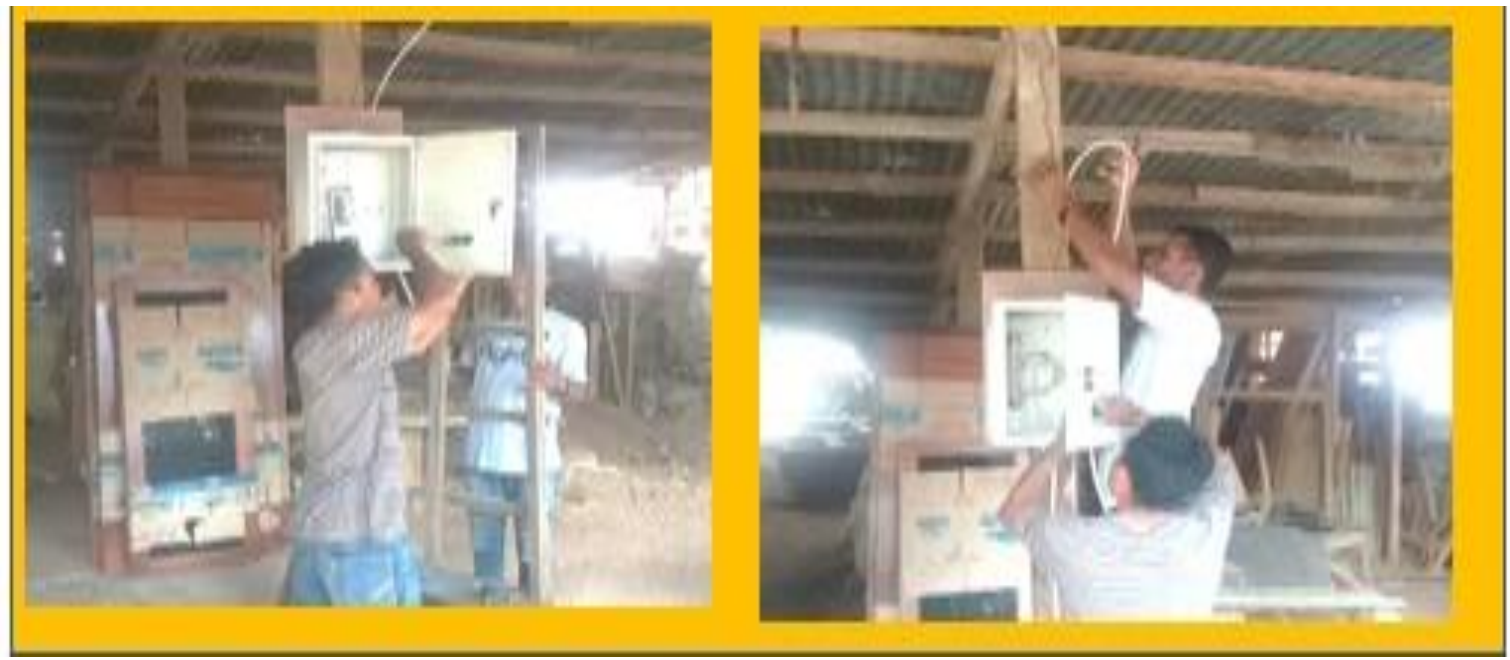

Gambar 13. Proses Pemasangan Instalasi Listrik Pada Workshop Mitra

\section{d. Pengujian Mesin Produksi}

Pada tahap ini semua mesin diuji untuk mengetahui tingkat kemampuan dari mesin-mesin. Selain itu, pengujian ini juga dilakukan untuk melihat apakah pemasangan bagian-bagian mesin sudah tepat pada posisinya, sehingga semua bagian dapat bekerja sesuai dengan yang diharapkan. Gambar pengujian peralatan yang diterapkan pada mitra dapat dilihat pada gambar 14 .

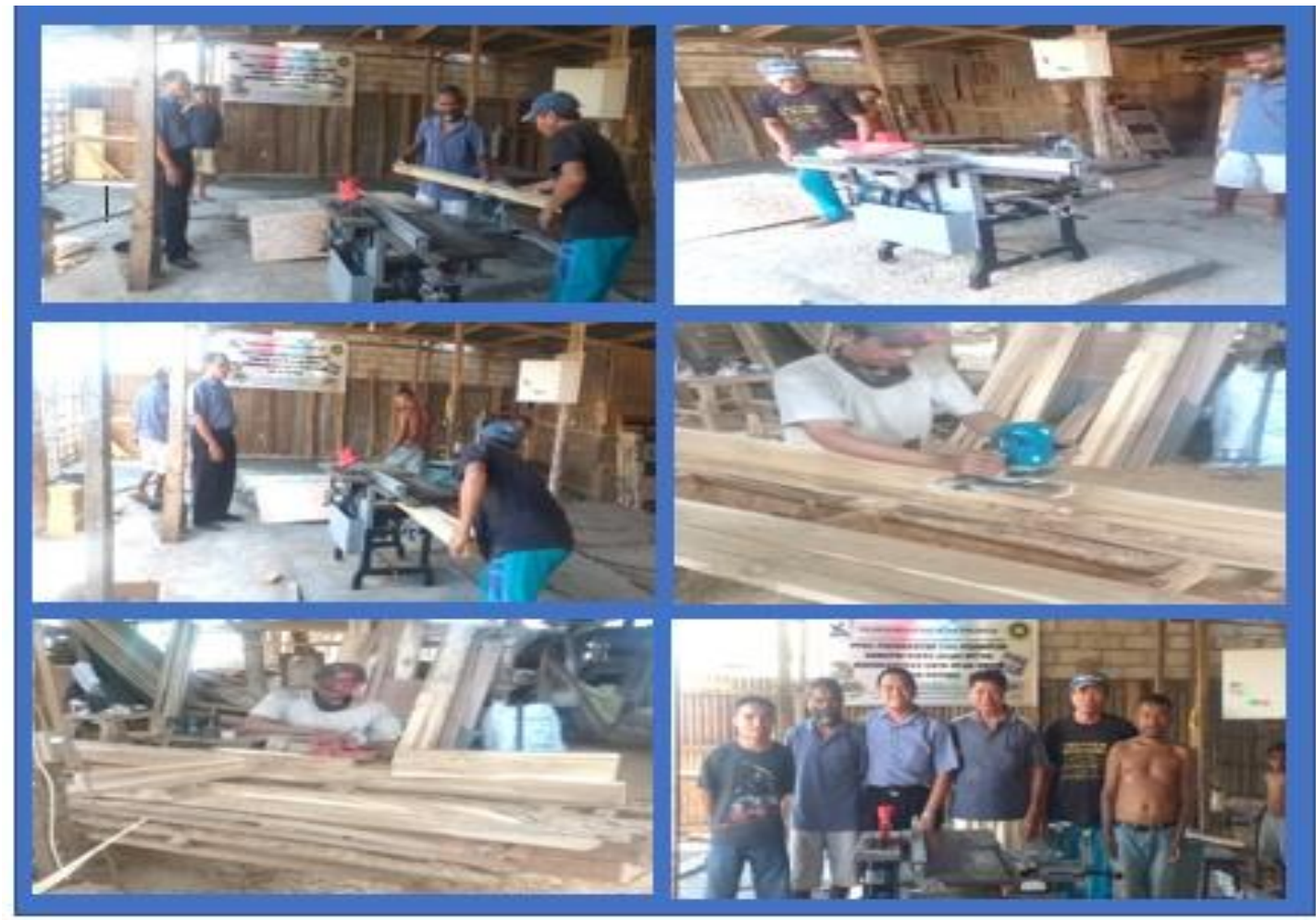

Gambar 14. Pengujian peralatan yang diterapkan pada mitra 
Setelah memastikan semua bagian mesin telah terpasang dan bekerja sesuai dengan fungsinya, maka tahap selanjutnya adalah menguji serta membandingkan kecepatan peralatan yang baru dengan peralatan kerja yang dimiliki sebelumnya oleh mitra.

\section{Analisis Hasil Capaian Kegiatan Tahun Pertama}

Dari hasil pendampingan dan monitoring ditempat kerja mitra diketahui bahwa, dengan adanya kegiatan PPPUD ini, mitra dapat mempercepat proses produksinya sampai tiga hari lebih cepat dari yang sebelumnya. Dengan membandingkan kecepatan produksi setiap jenis produk yang dihasilkan oleh mitra diketahui bahwa, dengan adanya kegiatan PPPUD ini, mitra dapat meningkatkan kinerja produksinya sampai 40 persen lebih cepat dari sebelumnya. Adapun hasil perbandingan peningkatan yang dicapai oleh mitra dapat dilihat pada gambar 15.

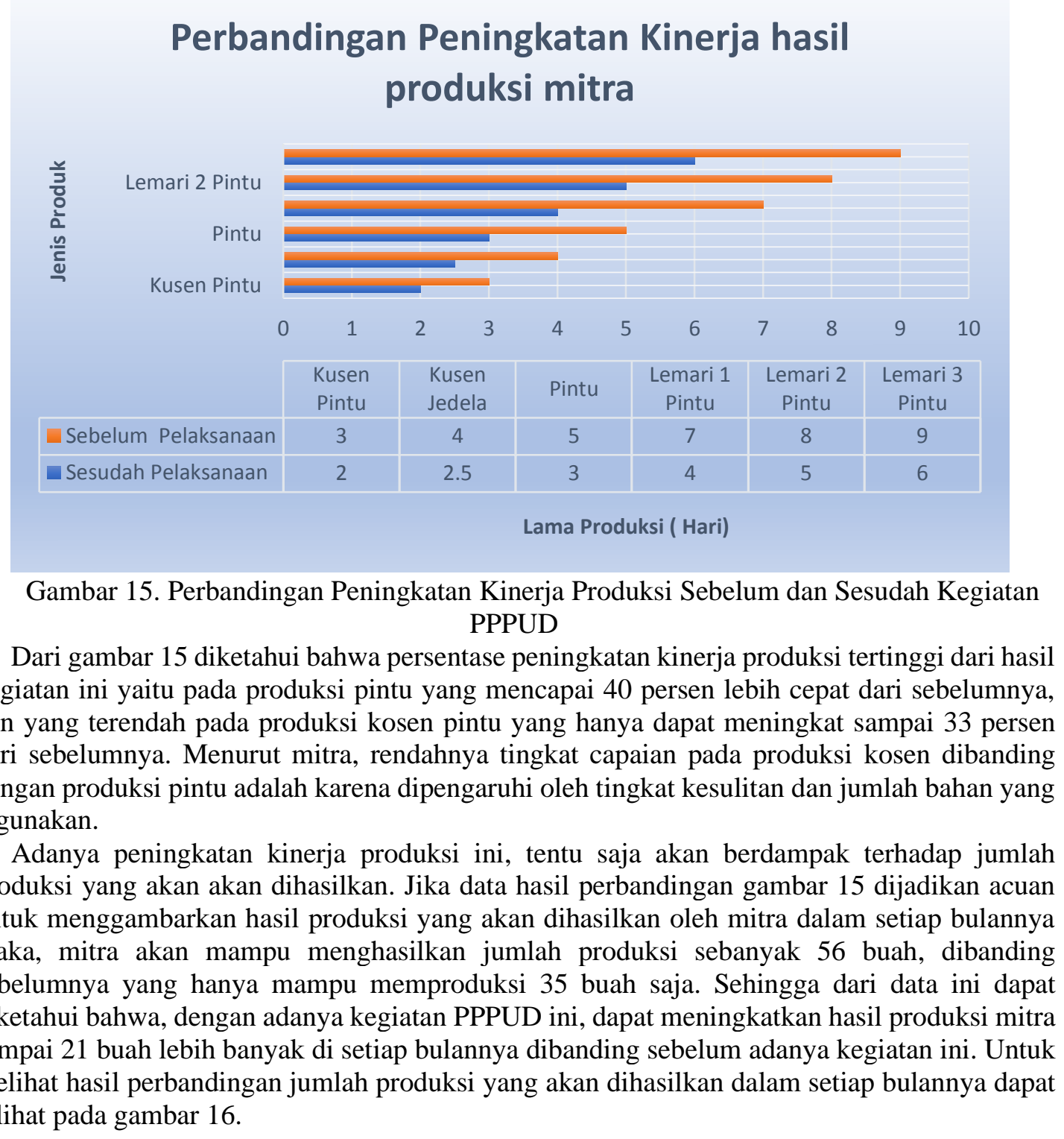




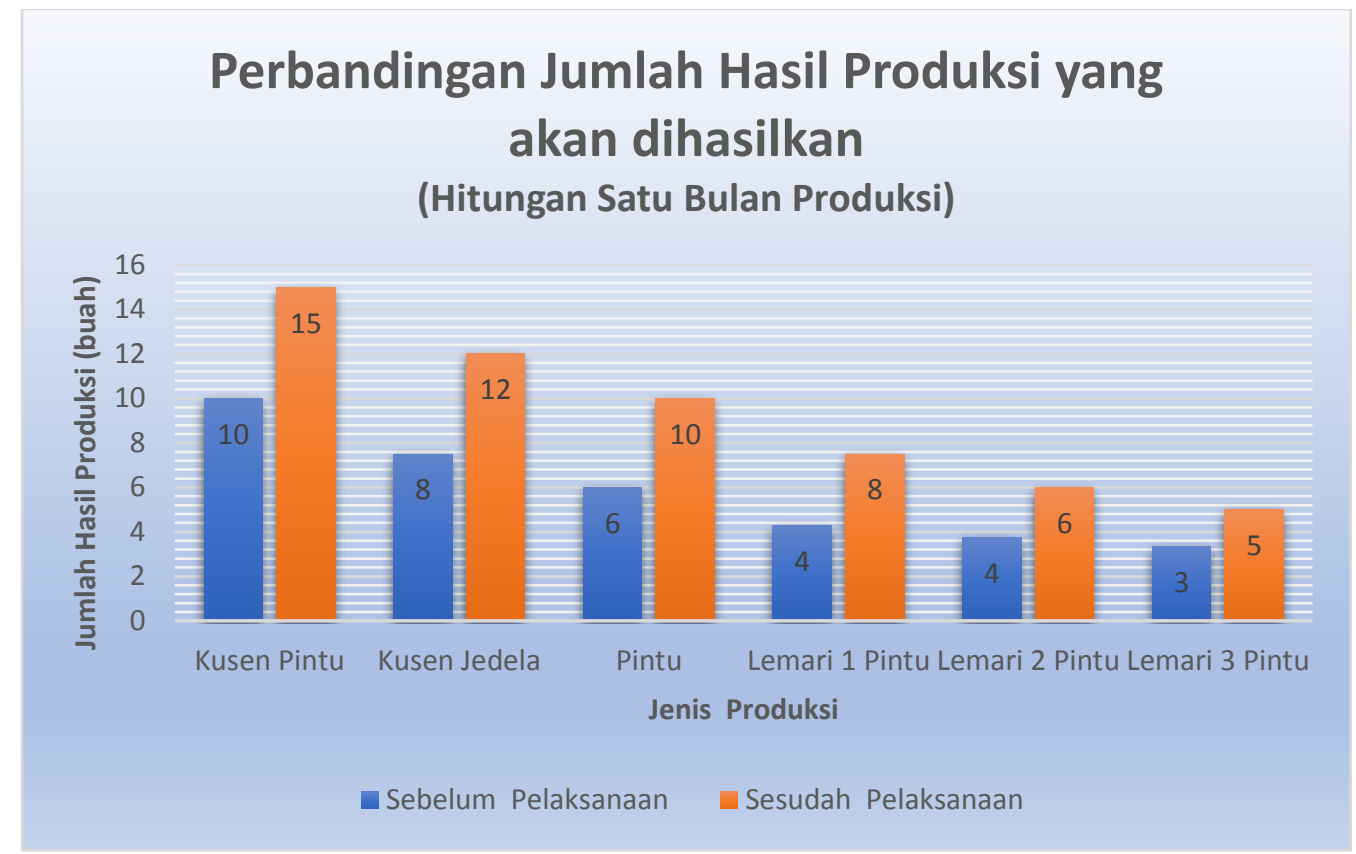

Gambar 16. Grafik prakiraan perbandingan jumlah produksi yang akan dihasilkan Setelah Kegiatan PPPUD

\section{KESIMPULAN}

Berdasarkan kegiatan PPPUD perbaikan dan peningkatan kualitas usaha mebel untuk meningkatkan daya saing UMKM kota kupang yang telah dilaksanakan dapat disimpulkan bahwa :

1. Mitra PPPUD mampu meningkatkan kinerja produksi sampai 40 persen lebih cepat dibanding sebelum kegiatan PPPUD ini dilaksanakan.

2. Pelaksanaan kegiatan PPPUD ini dapat membantu mitra meningkatkan jumlah memproduksinya sampai 56 buah dibanding sebelumnya, yang hanya mampu memproduksi 35 buah saja.

3. Program PPPUD ini telah dilaksanakan dengan capaian target sesuai dengan yang diharapkan yaitu adanya peningkatan produksi dibandingkan sebelum adanya kegiatan PPPUD ini.

\section{SARAN}

Dalam setiap selesainya pekerjaan, diharapkan agar mitra dapat memperhatikan perawatan mesin serta menjaga kebersihan mesin dari serbuk-serbuk kayu agar mesin dapat lebih awet sehingga kinerja mesin dapat tetap optimal.

\section{UCAPAN TERIMA KASIH}

Tim Pelaksana mengucapkan terima kasih kepada DRPM DIKTI yang telah memberikan dana sehingga pelaksanaan kegiatan ini dapat berjalan lancar sesuai dengan yang direncanakan. Selanjutnya tim Pelaksana juga mengucapkan terima kasih kepada Universitas Nusa Cendana khususnya Lembaga Penelitian dan Pengabdian Masyarakat (LP2M), yang senantiasa memantau dan memberi motivasi sehingga kegiatan ini dapat berjalan seperti yang diharapkan.

\section{DAFTAR PUSTAKA}

[1] Asrial. (2017). Laporan Tahunan IbPUD Usaha Makanan Ringan Camilan Khas NTT Dalam Menghadapi Era Masyarakat Ekonomi Asean MEA. Universitas Nusa Cendana.

[2] BPS NTT. (2017). Statistik Pertanian Provinsi Nusa Tenggara Timur 2017. (M. S. I Gede Made Suwartana, SST, Ed.). Kota Kupang: Badan Pusat Statistik Provinsi Nusa Tenggara Timur.

[3] Hunggurami, E., Utomo, S., \& Messakh, B. Y. (2016). Identifikasi Kuat Acuan Terhadap Jenis 
DINAMISIA - Jurnal Pengabdian Kepada Masyarakat Vol. 3, No. 2 Desember 2019, Hal. 258-265

Kayu yang Diperdagangkan di Kota Kupang Berdasarkan SNI 7973: 2013. Jurnal Teknik Sipil, 5(2), 175-184.

[4] POS KUPANG.COM. (2011). Mebel Kayu Jati Diminati Warga Kupang. Retrieved from http://kupang.tribunnews.com/2011/06/23/mebel-kayu-jati-diminati-warga-kupang

[5] POS KUPANG.COM. (2016). Iming-iming Laba Menggiurkan dari Budidaya Pohon Jati Putih. Retrieved from http://kupang.tribunnews.com/2016/08/04/iming-iming-laba-menggiurkandari-budidaya-pohon-jati-putih?page $=1$

[6] Sandhyavitri, A., Gunawan Wibisono, S. T., \& ST Rioputra, M. D. (2009). APLIKASI METODE VERTICAL DRAIN UNTUK STABILISASI TANAH DASAR LANDASAN PACU LAPANGAN TERBANG. Retrieved from https://www.researchgate.net/profile/Ari_Sandhyavitri2/publication/291766365_APLIKASI_ METODE_VERTICAL_DRAIN_UNTUK_STABILISASI_TANAH_DASAR_LANDASAN _PACU_LAPANGAN_TERBANG/links/56a8705b08ae0fd8b3fe9581.pdf

[7] Tanubrata, M. (2015). Bahan-Bahan Konstruksi Dalam Konteks Teknik Sipil. Jurnal Teknik Sipil, 11(2), 132-154.

[8] Usman, F. (2016). Masyarakat Ekonomi ASEAN ( MEA ) dan Daya Saing Investasi Indonesia. Jurnal Lingkar Widyaiswara, 3(1), 33-36.

[9] Wahyudi, I., Priadi, T., \& Rahayu, I. S. (2014). Karakteristik dan sifat-sifat dasar kayu Jati Unggul umur 4 dan 5 tahun asal Jawa Barat. Jurnal Ilmu Pertanian Indonesia, 19(1), 50-56.

[10] Zulyanto, A. (2016). Kesiapan Dalam Menghadapi Era Perdagangan Bebas Masyarakat Ekonomi ASEAN (MEA). Ekspansi, 8(1), 29-45. 